Review

\title{
Optical Sensing: the Last Frontier for Enabling Intelligence in Our Wired up World and Beyond
}

\author{
John CANNING*
}

\author{
Interdisciplinary Photonics Laboratories (iPL), School of Chemistry, 222 Madsen Building F09, The University of \\ Sydney, NSW, 2006 Australia \\ *Corresponding author: John CANNING \\ E-mail: john.canning@sydney.edu.au
}

\begin{abstract}
Consigned to the shadows of telecommunications, optical sensing has often taken a back seat in a young person's mind when considering the importance of photonics, or optics, to the advancement of the society and of knowledge. Here, I touch on briefly how broad optical sensing and sensing generally has become and how and why it is becoming the catalyst for the convergence of many technologies and in the process raising significant philosophical questions about the transformation of our society and indeed ourselves. In doing so I touch on many of the complexities in real life that influence the breakthroughs we see today, including a healthy speculation and critique on our society and an awareness of the motivations to improve it that drive many of them.
\end{abstract}

Keywords: Optical sensors, galactic village, global village, wireless, smartphones, science fiction, energy, medical, biodiagnostics, education, students, optical fiber

\section{Musings}

In this era of obfuscated measures of scientific outcomes and Elvish jargon, starry eyed young researchers can be forgiven for belatedly following the often recycled vision of a chosen few squeezed on the small, and steep, podiums of coveted awards [1]. How, in the midst of super massive, planet-hungry back holes, superluminal neutrinos, and god-like strings pulsating through space-time, and still-impending cataclysmic climate change, rendered the more stark by consuming inhalable chocolate [2], can optical sensing ever hope to compete for the limited pool of young genius (even as it brings solutions to all these spheres)? Do we have a bigger story to tell or do we too need to create "superhype"?

For "the 3rd Asia Pacific Optical Sensors (APOS
2012) Conference" held in 2012 in Sydney [3], I was asked to give a short introduction to the conference and outline some of its "vision" in bringing together all in optical sensing, outlining some of its vital cross-disciplinary appeal, and ensure a collegiate atmosphere where networking, collaboration, and genuine debate could take place. The response and interesting feedback I had after that presentation was encouraging, and the suggestion was made to put some of it in writing...

The competition for young minds has been around for millenia, or at least ever since Socrates lured his young cohorts into the delights of philosophical reasoning, somewhat more impressively than either Richard Dawkins or George Pell's battling for the title of who best prepares our young people for or against God or Gods in their somewhat fizzler of a Q \& A debate 2500 years later

Received: 22 May 2012 / Revised version: 5 June 2012

(C) The Author(s) 2012. This article is published with open access at Springerlink.com 
[4]. Reasoning is the foundation of science and engineering and indeed critical thought more widely. The ambiguity of false gods amongst our peers comes at a time when our world is entering an era of unprecedented change in which arguably optical sensing technology is central. This change is so profound within our increasingly connected global village but, somewhat amazingly, cognitively unrecognized more broadly even as it changes our physical being. Let me elaborate upon such musings.

\section{Galactic village}

In 1945, whilst bumbling around radar [5], Arthur Clarke (Fig. 1) postulated that it was possible to link up the world, in a so-called global village, with this new electromagnetic technology by using satellites in space. Following the work of Herman Potočnik on geostationary space stations [6], he went so far as to propose that the geostationary orbit, where a satellite could rotate with the Earth seemingly falling to the ground in such a way that it is always fixed above a particular location, would be ideal for communications [7]. This concept led to satellites, satellite communications and indeed to today's mobile networks - the "global village" (a term first coined by the Canadian artist Wyndham Price in 1948 [8]) was realized within his lifetime, something that is truly one of the more audacious and genuine landmark achievements in the history of combined human ingenuity.

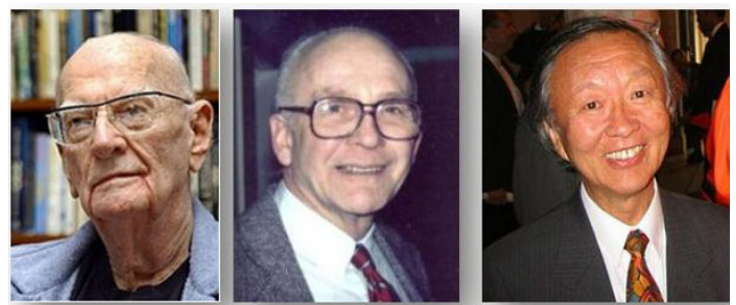

Fig. 1 Three pioneers (left to right): Arthur Clarke, Elias Snitzer, and Charles Kao (source: modified from web images).

\subsection{Philosophical disappointment with big ideas}

But technology on its own is often only a small part of greater and deeper philosophical conundrums.
Perhaps the saddest aspect was that we were yet to achieve one of Arthur's strongest convictions in-between scuba diving off the Barrier Reef [9], he believed that bringing the world together into such a global village would, in of itself, break human barriers and bring peace and harmony, forever preventing conflicts. Presumably, the dramatic and dirty stage of World War II played on his mind. In light of recent Nobel Prizes [10], we can sympathize with Arthur in this regard. That the global village idiot probably knew better than the Swedish Academy that he could never deliver, illustrates the dangerous "Maxwellian" mismeasure of the scientific outcome we seem to have come to accept [1]. Needless to say, such an unfulfilled destiny has rendered rebirth to ruminations of dynamite and arms manufacture as the basis of any integrous award.

\subsection{Sensing and communications}

The achievement of the global village represents much more than just the gossip between folks (though as Wikileaks revealed a lot of it there is [11]!). Optical sensing is in fact itself communications - it involves determining an important parameter and communicating this to machine and eventually to human. Indeed, the number of machines steps in between is steadily increasing today, raising another interesting challenge of disconnectedness between the end user and the measurement, perhaps the basis for the inopinate evolution of intelligent machines in the Terminator series [12]? We can in principle couple many sensors using this wireless network and it's not surprising many people today explore various aspects of such integration.

But for all the power of radio and other waves traversing across a transparent troposphere and stratosphere, the total number of sensors and their speed of operation are limited. If we compare the networks within our own brains, taking in sensory data from billions if not trillions of organic and 
molecular sensors all cabled together throughout our bodies, we see we are nowhere near the scale of activity required to achieve something really evolutionary - let us not think Lilliputian if we are to compete with string theory!

\subsection{Evolution of optical fiber sensing}

True evolutionary pressure, however, is coming from the convergence of wireless with a still relatively new technology - the optical fiber. I say relatively new because the world is only recently wired up comprehensively and even today the bandwidth is restricted in most parts of the world, its vast potential remaining unleashed. (overwhelmingly for commercial rather than technical reasons - many telecomm. companies want to continue making vast profits on copper cable systems for at least another decade or three). However, optical fibers for imaging applications were discussed decades earlier and patented by Hansell in 1927 [13], a reminder that optical tools for diagnostics drove much of the early development of the technology we associate more with telecommunications today. This work, along with earlier developments on rod transmission of television images, can be traced further back to some of the earliest optical waveguide rod probes used for illumination, in particular of body cavities in 1888 [14, no primary reference provided]. This constituted some of the earliest work in biophotonics culminating today with the optical snapshots of cancer unveiled by David Sampson and Kelsey Smith at APOS 2012 using significantly more sophisticated and active fiber needle probes $[15,16]$. Over a time span of more than 130 years, we can but marvel at the enduring and evolving legacy of imaging research and speculate what it will bring tomorrow, preferably lubricated with the enlightenment-bringing Western Australian Little Creature's ale.

Although the underlying concept of the optical fiber was invented in some form or another much earlier [14, 17], its potential as a game changing waveguide was only first recognized in the 1960s by extraordinary pioneers such as Elias Snitzer (Fig. 1), who evaluated theoretically the single mode fiber [18] to explain the behavior of those first made by W. Hicks, P. Kiritsy, and C. Thompson at Mosaic Fabrications, USA [14, no primary reference provided]. As part of the ridiculously golden era of highly well funded industrial research laboratories, Snitzer went on to invent and fabricate other key technologies including fiber amplifiers and lasers [19] (glass recognized to be a low loss host for rare earths). The first application of these technologies was improving optical detection using lidar [20] not without some truth, optical sensing enabled telecommunications, something we don't always appreciate today. These developments paved the way for active components and fiber fabrication developed by the interesting collection of decussating disciplinary experts Cliff Fonstad, Robert Maurer, Peter Schultz, Donald Keck, and Frank Zimmer [21]. They themselves were emboldened by calculations and measurements on silica brought to Corning by Charles Kao [22] (though no reference was made), who in turn was directed to pursue the search for low loss materials by his mentor George Hockham [23] (possibly one of the quickest undeservedly unrecognized figures in the history of the optical fiber). In fact Charles Kao (Fig. 1) was picked, perhaps by the spin of a roulette wheel, from this menagerie of achievers to get the official, global recognition - the Nobel Prize in Physics (not chemistry?). Today, optics, or photonics to be more precise, has come of age and in doing so has opened up hitherto new possibilities across nearly all areas of human endeavor (or travail). Closer to home, fiber sensing has certainly exploded and made its presence in the field of optical sensing more generally felt, even if the commercial uptake remains relatively small beyond data transmission.

But there is always more: at the 3rd Asia Pacific Optical Sensors Conference, Allan Lau enthralled us with the convergence of photonics and aerospace vehicles, describing the work towards smart sensor 
networks embedded within new composites of our newfangled aerospace vehicles [24]. These are amongst the first steps towards introducing the sensory network required to turn flying machines smart, with all the implications that has (as I write this, almost certainly one of Barak's hapless drones is taking full sovereignty of wireless and optical sensing to cause all manner of mischief thousands of kilometers away, further frustrating his predetermined journey of peace).

\subsection{Reaching out}

With the optical fiber, in the ground and in the sea, soon joining wireless in the air and space, our planet and its immediate surroundings are truly wired up on an unprecedented scale. With missions to the Mars and other extraterrestrial visitations on a quest using optical sensing to look for any native life forms [25] that could pose a problem for mining and real estate expansion programs, this network looks to become not only a global village but a galactic one (the demands for superluminal velocities will surely increase). And behind it all will be diagnostics, particularly optical - even our mobile phones require light emitting diodes (LED), organic LEDs (OLED), active matrix LEDs (AMOLED) etc) and charge coupled devices (CCD) and compound metal oxide semiconductor (CMOS) (arrays most often used as cameras but increasingly used as optical sensors in their own right [26]. All of this brings a potential capacity and capability, when operating together, that makes machines and networks smart, smarter together, and used widely finally bringing, in my view, a genuine new evolutionary pressure to real change within us. But perhaps not quite the way Arthur envisaged - after all evolution has never shown any commitment to progress or improvement.

\section{Smarter Grid}

\subsection{Scale and privacy}

These networks that span so far, perhaps in the future in every nook and cranny we look in, will essentially resemble increasingly the same smart grid of neurons that fill our heads with fanciful thoughts (or if you are an Android electric sheep [27]), most of which we deem sufficiently sensitive enough to keep private. Privacy is in fact another one of the great challenges people like Mark Zuckerberg kindly reminds us through his Facebook [28], growing like a pervasive electronic weed in our internet jungle, affording a novel route to defeat the resistance to Orwell's long overdue 1984 [29]. In fact, with the luxury of having all kinds of sensors with capabilities that exceed ours being steadily integrated into an increasingly complex network run by increasingly organic software, it may not be so long before our wireless and optical grids are really smart - smarter grids than our own that could reach deep into space.

\subsection{Pervasiveness and optical sensing}

The biggest practical challenges of the Smarter Grid are technical in nature - as the system grows so too does the need to overcome or exploit obstacles or challenges such as loss, nonlinearities, cross talk, signal encoding and more. Some of the solutions offered by researchers such as Xiaoyi Bao (Fig. 2) in controlling Brillouin frequency shifts and fluctuations [30] for the immediate application to optical sensing will also play an important part in resolving more broadly many of these challenges. In turn, Brillouin sensors could be one very useful

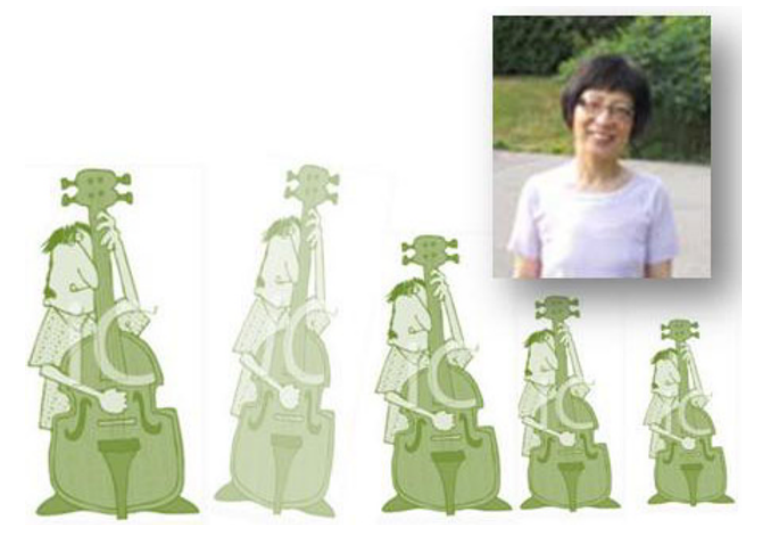

Fig. 2 Controlling those frequency shifts and fluctuations for effective Brillouin sensing - Xiaoyi Bao [30]. 
technology at the sensory end of the narcissistic Smarter Grid monitoring structural health of buildings, power plants, homes, refrigerators, massage chairs and more before and after natural disasters such as windmill-thrashing hurricanes in the United States and nuclear-busting tsunamis in
Japan and Indonesia. The Smarter Grid will also handle concomitantly, and by now enthusiastically, our health systems; for example, a patient being sharply imaged for internal cancers using David Sampson's on-line, pain-free optical fiber imaging needles (Fig. 3) [15].

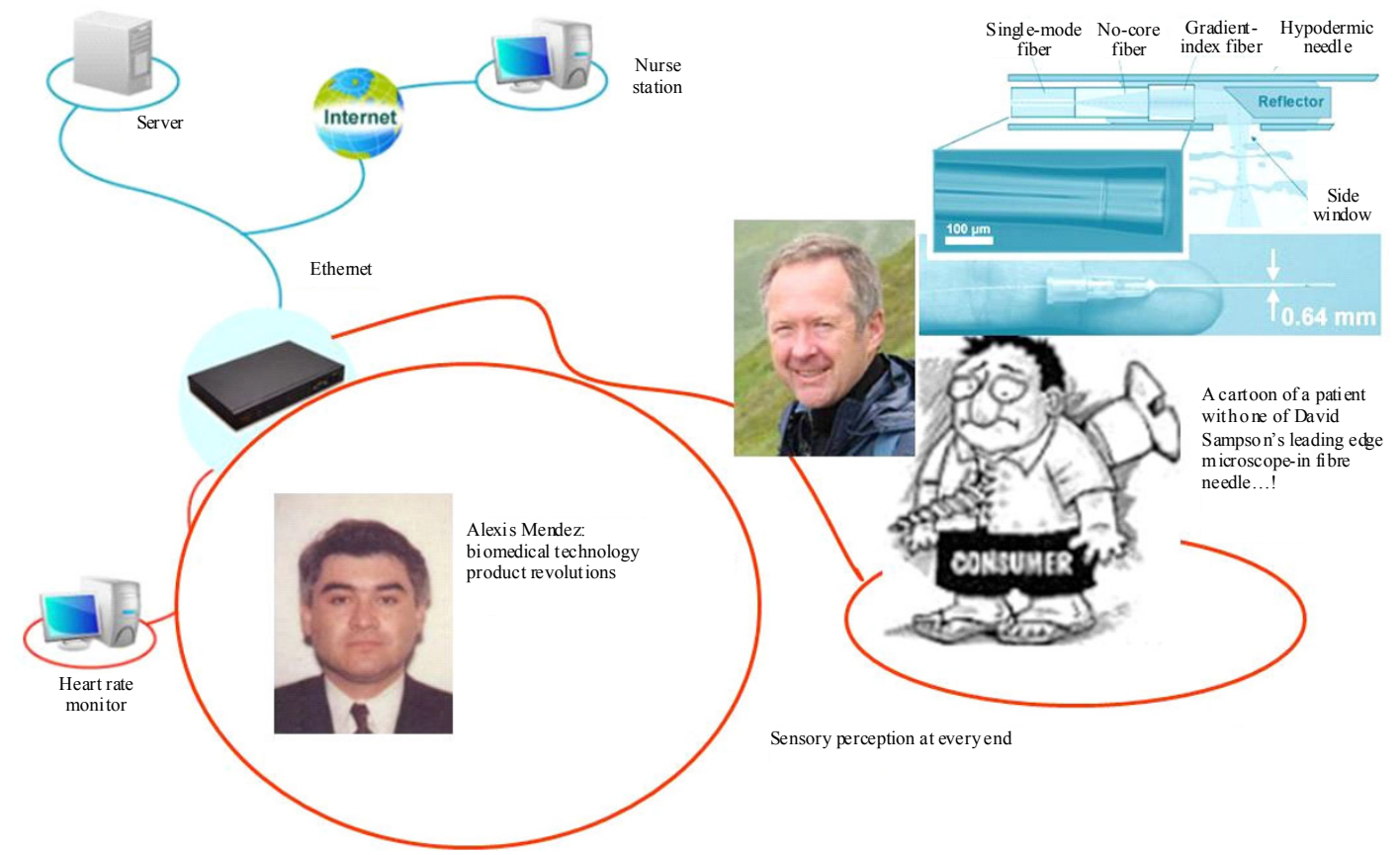

Fig. 3 A medical SmartGrid and where new technologies may fit (actual image of a fiber needle is adapted from [31].

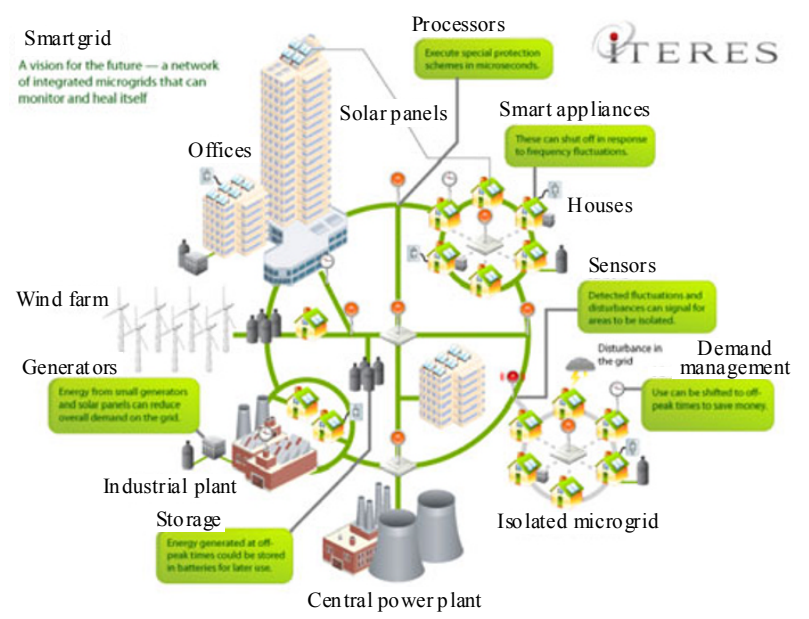

Fig. 4 An example of an energy SmartGrid (source: http://www.iteresgroup.com/services/smart-grid/).

Arthur and Stanley Kubrick again remind us that a computer that reaches the threshold of intelligence may in fact develop neuroses [32] thus the cogitative unease that our local medical centers are unlikely to improve under machines. In any case, the "smarter" grid (Fig. 4) will be able to integrate millions, or billions if not more, of new sensors across our galactic village, no matter the type. In fact, Alexis Mendez (Fig. 3) gave us significant insight at the range of technologies being explored and commercialized today [33].

\section{Predicting the future}

\subsection{Evolution with regression}

The internet today has already spun into an incredible new world of overwhelming human activity that would not have been conceived by its creators - the very fact that human interconnectedness can be manipulated and directed, and even transformed and trivialized, by purely electronic data gathering and sharing such as achieved by Facebook and Wikipedia, for example, is telling. Mike Keefe's humorous evolutionary plot 
(Fig. 5) summarizes some of the immediate concerns for everyday people [34]. What impacts society is not necessarily the fantastic new technology, indistinguishable perhaps for many people from magic, but its use and the more degrees of freedom the more unpredictable that use can become.

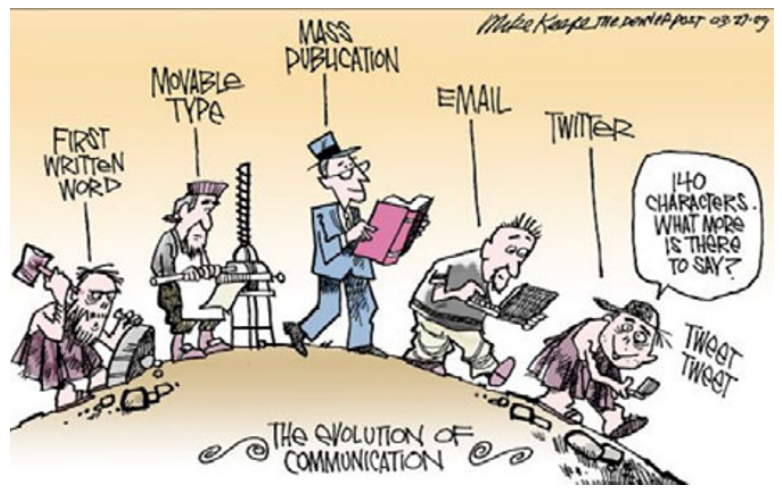

Fig. 5 Mike Keefe, Cartoon, [34] (image source: http://www.intoon.com/cartoons.cfm/id/68559).

\subsection{Impact of intelligent networks}

Not so SmartGrids originated (Fig. 6) and have been developed largely within universities [35], with innovations often funded by defense, so it is not surprising that much of what we see today, both the hardware and applications, has spun out from them. Apple and Microsoft, for example, largely owe their technologies to ideas and solutions developed within the university environment and within large research laboratories from a peculiar and exclusive golden era of industrial research within the United States that seems to have gone the way of an Aristophanes play [36].

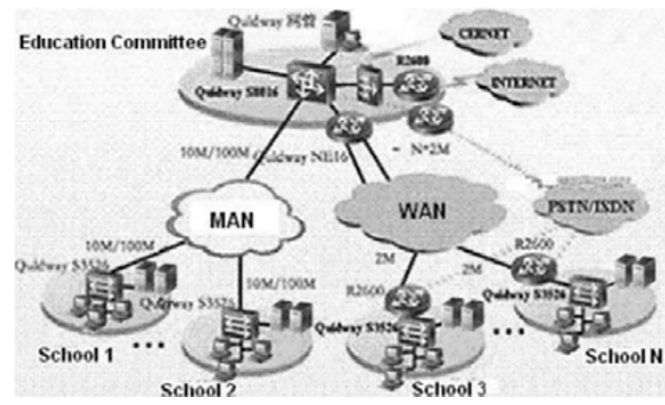

Fig. 6 A school educational SmartGrid (source unknown).

But the next generations will be significantly different - data accumulation and sharing, where impact seems highest, does not require a university degree (although a philosophy degree may help), and much of the technology driving the internet is open and available to all. New concepts and opportunities accessible to all are appearing all the time (Fig. 7), such as Google's Android open access software [37] along easily programmable state of the art optical components within mobile phones [26]. The degree of unpredictability and potential is growing. One of the most transformative examples in terms of cognitive impact, of significant political and philosophical originality, has to be the very existence and success of Wikileaks to date, achieving more in news reporting and freedom in its short lifetime than the entire history of modern reporting [38]. Remarkably, it broke out from a largely insular hacking environment of largely young people with nothing else to do, making it a genuine precursor for something that is perhaps the antithesis of Big Brother in 1984 [29]. Of course, the caveat being that any data accumulation and sharing, no matter the initial good intentions, can easily become Big Brother, or just destructive, through human, or machine, neurosis (the extraordinary behaviour of Daniel Domscheit-Berg in crippling Wikipedia, whilst mired in denigrating gossip

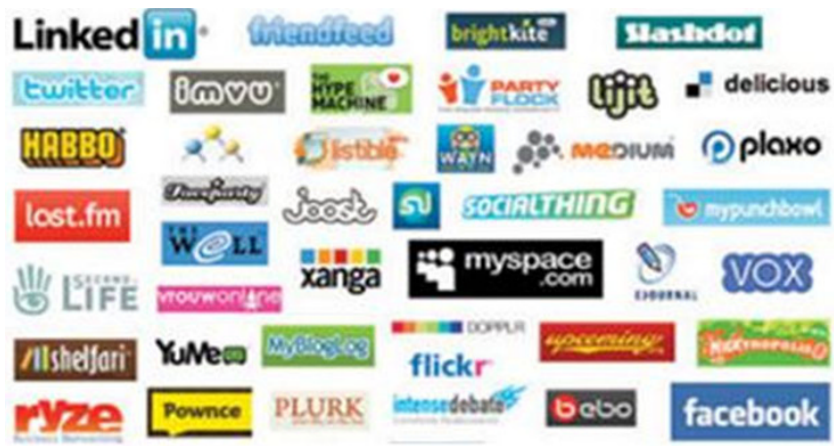

Fig. 7 Generation of software paradigms that are impinging on culture and educational transformation through commercial enterprise is sending signals of the potential for a strong change in education where the past pre-eminence of universities and other institutions, and their relevance, is challenged. Of particular note is the increasing association of opportunistic software entrepreneurship with technology and intellectual capacity once associated only with the university educated; a "brain drain" from Australia [40]. 
accusing Assange of having sex with his cat in his book [39], illustrates this amply). The role that the young generation plays remains as critical and as profound as the role an intelligent machine like HAL [32] may play in the future.

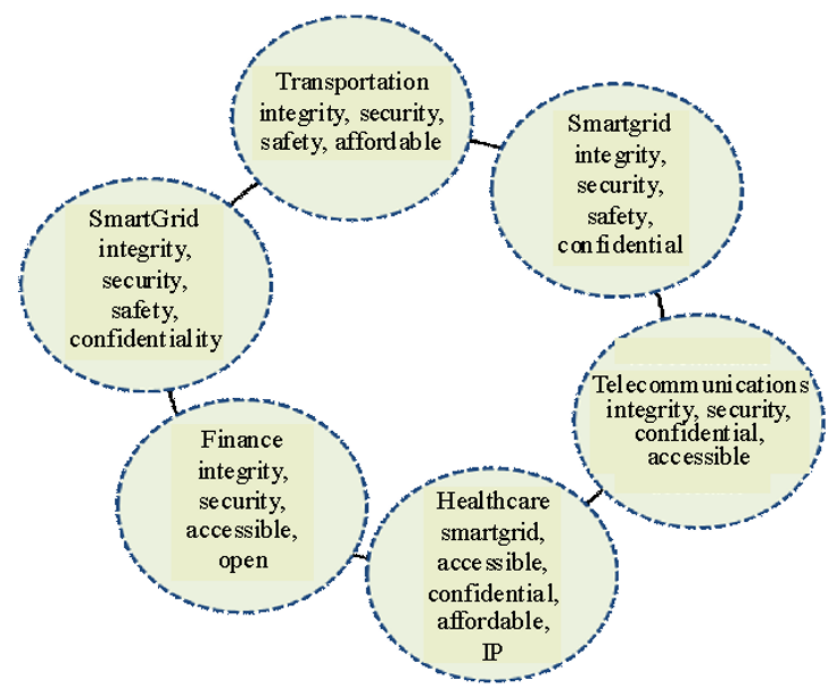

Fig. 8 Technology poses equally important evolving challenges across the entire spectrum of society: political, economic, legal, education, social, and motivational.

\subsection{Social and biological consequences}

In short, the data collecting technology is the heart of it all, and much of this data collecting technology can invariably be described as being collected by the sensing technology. It therefore impacts our social, legal and humanitarian culture, our politics, our economics, our education, and our health (Fig. 8) - it has taken a much broader role in complementing the limits of our own organic machinery in extending and sharing the diagnosis and manipulation of our world. So profound is the impact of this sensory extension that there is some evidence it is already changing us physically. For example, memory is being lost by a significant portion of the current young generation as they rely more and more on external information sources such as smartphones and other access pathways to internet derived information reservoirs (such as Wikipedia) rather than their own brains [41]. The human brain appears to be responding to this by actually shrinking, perhaps leading to a future generation of Alzheimer ridden, Wii playing teenagers (Fig. 9). The impact on pattern identification and therefore some profess will be profound, at least until we can embed such reservoirs directly into our brains.

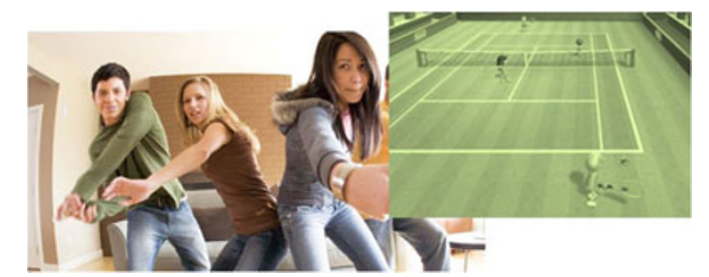

Fig. 9 Wii-playing teenage bipeds perhaps struggling to remember tennis moves after memory loss using smartphones (image source: http://www.sjcpls.org/calendar/2011-12-30).

In parallel, a new generation of less pretty nerds and geeks are appearing. They are long outcast from the social norms of the society and many spend their time buying lego mindstorms undertaking robotic experiments that would make some engineering professors cry in shame. In addition to accelerating the Terminator's age of the machines [12], they are effectively establishing the skills needed to take control of their empty, usually prettier, peers in new and clever ways. Thus rather than the utopian ideals we, and Arthur, would hope a galactic village brings, the internet may catalyse the earlier prediction by $\mathrm{H}$. G. Wells in 1895 of a future society run by subsurface Morlocks (having survived a "carbon ruined" world) feeding on the mindless but youthful and pretty Eloi (Fig. 10), the one our hero prefers [42] much to the admonishment of our Big Bang nerds [43] well into the future yet again.

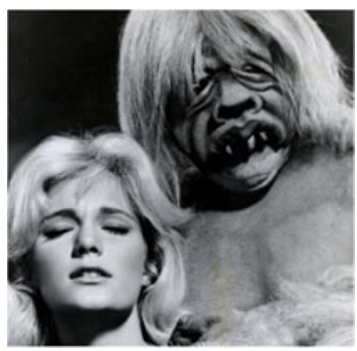

Fig. 10 Speculations and stereotypes into the future - H.G. Wells Time Machine [41]: the pretty Wii-playing Eloi subjugated by the less attractive, and therefore evil and nerdier, Morlocks (image source: 1960 film version http://www.clubdesmonstres.com/best/htm/morlock_1960.html). 


\section{Conclusions}

Through reflection and musings I have attempted to convey the potential impact on optical sensing, because of its commonality to our dominant personal sensor mode (we use our eyeballs as optical sensors to detect the information on our smartphones, which may also be using optical sensing, for example), will have on our society. That is impact beyond the immediate function of data gathering; rather laying the groundwork for how we function as a society in the future and how we transform even ourselves when we effectively extend our sensory input (perhaps whilst simultaneously diminishing our existing ones). Some of it is genuinely unpredictable; but all of it needs continual consideration but just as recently the significant ethical controversy surrounding the publication of the first synthetic malaria virus led to it being withheld subject to further debate [44]. This is a timely and important reminder that each new generation of young optical scientists and engineers needs to consider issues that may appear to go beyond their specific sphere of interest. This is especially important given they are entering an era where their non-university educated peers may indeed be able to exploit, on a grander scale, their own technology developments ahead of them if they don't spend the time considering these big picture challenges. That they can do this with largely a lack of a broader education is hardly surprising because the monetary gains provide a very valuable incentive for people to create much focused opportunities regardless of their background. But education (and these days it can be obtained independent of the universities, even on-line) and foresight built on something more than money are important because monetary driven opportunities are nearly always short-sighted and are rarely able to be stopped if something goes awry.

I have indirectly hinted that some guidance towards the broader, long-term impact of science, engineering and technology may be gained by revisiting old and new science fiction where futuristic concerns and directions can always be re-evaluated with new inputs and insights as time goes on and form different sections of our community. There is a need for a generation of new visionaries and "wise ones" (perhaps equivalent to Aboriginal elders of Australia who may have likely developed a visionary culture in the spiritual domain by ingesting hallucinatory indigenous "pituri" nicotine [45]). Good science and engineering for tomorrow's galactic village still requires integrity and a decent set of ethics and standards based on having a larger picture and a set of role models, perhaps something more than the type to earn Maxwellian wrath [1].

Open Access This article is distributed under the terms of the Creative Commons Attribution License which permits any use, distribution, and reproduction in any medium, provided the original author(s) and source are credited.

\section{References}

[1] I. Maxwell, "Measuring science outcomes," in Chemistry in Australia (Royal Australian Chemical Institute), Views, technology and innovation, pp. 40, 2012.

[2] http://www.davidideas.com/details/Idea_15_Le_Whif as_Commercial_Product; reported in http://www.news.com.au/entertainment/restaurants-ba rs/chocolate-without-calories-its-finally-arrived/storyfn93ypt9-1226353111364

[3] Editors: J. Canning, G. D. Peng, 3rd Asia Pacific Optical Sensor Conference, Sydney NSW, Australia 2012, www.apos2012.org.

[4] http://www.theage.com.au/entertainment/tv-and-radio /dawkins-shades-pell-in-battle-of-belief-20120410-1w 1k9.html; the debate can be watched here: http://www.abc.net.au/tv/qanda/txt/s3469101.htm.

[5] A. C. Clarke, Glide Path (non-fiction), 1963, various editions exist since.

[6] H. Potočnik, Das Problem der Befahrung des Weltraums - der Raketen-Motor (The Problem of Space Travel - The Rocket Motor), Berlin, 1928; Published partially in 3 parts in the United States' Science Wonder Stories, 1929. 
[7] A. C. Clarke, "Extra-terrestrial relays," Wireless World, vol. 51, no. 10, pp. 305-308, 1945.

[8] W. Lewis, America and the Cosmic Man (non-fiction). Doubleday, USA, 1948.

[9] A. C. Clarke, Coast of Coral (Blue Planet Trilogy) (non-fiction), I Books, UK, 1955 (reissued many times with new editions to be available soon through Amazon).

[10] Barak Obama, Nobel Peace Prize, 2009 (http://www.nobelprize.org/nobel_prizes/peace/laure ates/2009/press.html).

[11] Wikileaks releases US cables, 2010; http://www.wikileaks.org/cablegate.html; J. Crace, "WikiLeaks cables show diplomacy is a madhouse: International relations are as gossip-rich as we'd imagined, US embassy cables reveal", The Guardian, 2010;http://www.guardian.co.uk/media/2011/feb/08/ wikileaks-cables-diplomacy-madhouse.

[12] J. Cameron (Director), The Terminator (science fiction movie). United States: Helmdale Film Corporation, 1984.

[13] C. W. Hansell, "Picture transmission," U. S. Patent 1751 584, March 25, 1930.

[14] N. Madamopoulos, "Optical communications: 32 centuries in the making," Journal Student Research, vol. 3, pp. 67-72, 2010; no primary source was supplied.

[15] D. D. Sampson, "Human cancer imaging with optical coherence tomography microscope-in-a-needle technology," (Plenary talk) prsented at 3rd Asia Pacific Optical Sensors Conference (APOS 2012), Sydney, Australia, Jan. 31-Feb. 3, 2012.

[16] K. M. Kennedy, B. F. Kennedy, R. A. McLaughlin, and D. D. Sampson, "A new method of optical biopsy: demonstration of mechanical contrast in deep tissue using an optical coherence elastography needle probe," (Post-deadline paper) presented at 3rd Asia Pacific Optical Sensors Conference (APOS 2012), Sydney, Australia, Jan. 31-Feb. 3, 2012.

[17] J. Hecht, City of light: the story of fiber optics, 2nd ed. Oxford: Oxford University Press, 2004 (a broader, more insightful read from a personal perspective on the history of telecommunications and optical fibers is A.C. Clarke, How the world was One: Beyond the Global Village, Bantam UK, 1992).

[18] E. Snitzer, "Cylindrical dielectric waveguide modes," Journal of Optical Society Of America, vol 51, no. 5, pp. 491-498, 1961; E. Snitzer and H. Osterberg, "Observed dielectric waveguide modes in the visible spectrum," Journal of Optical Society of America, vol. 51, no. 5, pp. 499-505, 1961.

[19] E. Snitzer, "Proposed fiber cavities for optical masers," Journal Applied. Physics, vol. 32, no. 1, pp. 36-39, 1961; C. J. Koester and E. Snitzer, "Amplification in a fiber laser," Applied Optics, vol. 3, no. 10, pp. 1182-1186, 1964; E. Snitzer,
"Glass lasers," Applied Optics, vol. 5, no. 10, pp. 1487-1499, 1966.

[20] G. C. Holstl and E. Snitzer, "Detection with a fiber laser preamplifier at $1.06 \mathrm{p}$," IEEE Journal of Quantum Electronics, vol. 5, no. 6, pp. 319-320, 1969.

[21] http://www.sff.net/people/jeff.hecht/chron.html; this chronological summary provides a somewhat eye-raising insight behind the three papers associated with the development of the optical fiber where the Corning contributions are recorded much more narrowly. Notably, the contributions of Kao in triggering this work by approaching Corning are absent as is a reference to the $1966 \mathrm{Kao}$ and Hockham work - this potentially highlights significant ethical challeng es created by commercial interests: P. Kapron, D. B. Keck, and R. D. Maurer, "Radiation losses in glass optical waveguides," Applied Physics Letters, vol. 17, no. 10, pp. 423-425, 1970; D. B. Keck, P. C. Schultz, and F. Zimar, "Attenuation of multimode glass optical waveguides," Applied Physics Letters, vol. 21, no. 5, pp. 215-3217, 1972.

[22] C. K. Kao and G. A. Hockham, "Dielectric-fiber surface waveguides for optical frequencies," in Proc. Instn. elect. Engineers, vol. 113, no. 3, 1966, pp. 191-198, 1966; K. C. Kao and T. W. Davies, "Spectrophotometric studies of ultra low loss optical glasses I: single beam method," Journal Physics E: Scientific Instrument, vol. 1, no. 11, pp. 1063-1068, 1968; J. Lytollis, C. K. Kao, and G. I. Turner, "Infra-red optical communications system," Infrared Physics, vol. 8, no. 1, pp. 123-129, 1968.

[23] G. A. Hockham wins the Rank Prize for the work he and Kao did on suggesting the use of waveguides.

[24] A. K. T. Lau, "The potential of embedded sensor technologies in NASA's aerospace applications," presented at 3rd Asia Pacific Optical Sensors Conference (APOS 2012), Sydney, Australia, Jan. 31-Feb. 3, 2012.

[25] V. Parro, G. D. Diego-Castilla, J. A. Rodríguez-Manfredi, L. A. Rivas, Y. Blanco-López, E. Sebastián, et al., "SOLID3: a multiplex antibody microarray-based optical sensor instrument for in situ life detection in planetary exploration," Astrobiology, vol. 11, no. 1, pp. 15-28, 2011.

[26] J. Canning, M. Naqshbandi, and M. J. Crossley, "Measurement of rhodamine B absorption in self-assembled silica microwires using a tablet as the optical source," presented at 3rd Asia Pacific Optical Sensors Conference (APOS 2012), Sydney, Australia, Jan. 31-Feb. 3, 2012; J. Canning, A. Lau, M. Naqshbandi, I. Petermann, and M. J. Crossley, "Measurement of fluorescence in a rhodamine-123 doped self-assembled 'giant' mesostructured silica sphere using a smartphone as optical hardware," Sensors, vol. 11, no. 7, pp. 7055-7062, 2011. 
[27] P. K. Dick, Do Androids Dream of Electric Sheep (science fiction), 1968, published by many distributors (listed on most sites such as Amazon).

[28] E. Steel and G. A. Fowler, "Facebook in privacy breach top-ranked applications transmit personal IDs, a journal investigation finds," The Wall Street Journal, Oct. 17, 2010; C. M. Hoadley, H. Xu, J. J. Lee, and M. B. Rosson, "Privacy as information access and illusory control: the case of the facebook news feed privacy outcry," Electronic Commerce Research \& Applications, vol. 9, no. 1, pp. 50-60, 2010.

[29] G. Orwell, 1984 (science fiction), 1950.

[30] X. Bao, S. Xie, X. Liu, and L. Chen, "The non-uniformity and dispersion in SBS-based fiber sensors," presented at 3rd Asia Pacific Optical Sensors Conference (APOS 2012), Sydney, Australia, Jan. 31-Feb. 3, 2012.

[31] D. D. Sampson, B. C. Quirk, A. Curatolo, L. Scolaro, R. W. Kirk, D. Lorenser, et al., "Microscope-in-a-needle technology for deep-tissue 3D imaging," (Inv. talks) in Information Photonics 2011, Ottawa, Canada, pp. 1-2, 2011.

[32] A. C. Clarke, 2001: A Space Odyssey (science fiction), 1968; Concurrently with S. Kubrick (director), A. Clarke \& S. Kubrick (Script), movie version 2001: A Space Odyssey, 1968.

[33] A. Mendez, "Fiber optic biomedical sensors: principles, trends \& applications," presented at $3 \mathrm{rd}$ Asia Pacific Optical Sensors Conference (APOS 2012), Sydney, Australia, Jan. 31-Feb. 3, 2012.

[34] M. Keefe, "The evolution of communication," Cartoon, The Denver Post, United States, 2009 (http://www.intoon.com/\#68559).

[35] J. C. R. Licklider, "Man-computer symbiosis," Transactions on Human Factors in Electronics, vol HFE-1, no. 1, pp. 4-11, 1960.

[36] http://www.gutenberg.org/ebooks/2562; Aristophanes' play The Clouds (423 B.C.) has been lost and its current translation, from 1970 , is thought to be inaccurate; it was the play which satirized Socrates and which Plato in his work The Apology accused of precipitating the subsequent execution of Socrates in 399 B.C. [the merits of the accusation are still debated but it is likely it brought unnecessary attention to him); recent translation by B. Jowett, ebooks@adelaide (2006), updated 2010].

[37] Android Open Source Project, http://source.android.com/.

[38] A very well written piece that fills in gaps missing in other articles is R. Manne, "The cypherpunk revolutionary: Julian Assange," originally published in The Monthly (2011), reproduced in The Best Australian Essays 2011 (Ed. R. Koval), Black Inc Victoria, Australia, 2011.

[39] D. Domscheit-Berg, Inside WikiLeaks: my time with Julian Assange at the world's most dangerous website. Melbourne, Victoria, Australia: Scribe Publications, 2011.

[40] A. Moses, "Brain drain: why entrepreneurs leave home," \& "Tech exodus: what you say about the brain drain crippling Australia's tech industry," Sydney Morning Herald (newspaper), May 18, 2012, available at http://www.smh.com.au/technology/ technology-news/tech-exodus-what-you-say-about-thebrain-drain-crippling-australias-tech-industry-20120518 -1yud7.html\#ixzz1vBoX9ttu.

[41] B. Sparrow, J. Lui, and D. M. Wegener, "Effects on memory: cognitive consequences of having information at our fingertips," Science, vol. 333, no. 6043, pp. 776-778, 2011.

[42] H. G. Wells, The Time Machine (science fiction novella), 1895 [republished many times since search Amazon; made into two films (British MGM1960; DreamWorks/Warner Bros 2002 - first is recommended) and television film, 1978, Sun Classic Pictures, 1978].

[43] C. Lorrre, B. Prady, Big Bang, http://www.tv.com/ shows/the-big-bang-theory/ (fiction comedy).

[44] V. Hackenbroch and G. Traufetter, SPIEGEL Online: http://abcnews.go.com/health/super-flu-controversy-bre ws-scientists-creation-killer-viruses/story?id=15721283 and http://www.rushfm.co.nz/?page id=1216.

[45] A. Ratsch, K. J. Steadman, and F. Bogossian, "The pituri story: a review of the historical literature surrounding traditional Australian aboriginal use of nicotine in central Australia," Journal of Ethnobiology and Ethnomedicine, vol. 6, no. 2, pp. 1-13, 2010. 